\title{
LIXIVIAÇÃO DO GLYPHOSATE E DO IMAZAPYR EM SOLOS COM DIFERENTES TEXTURAS E COMPOSIÇÃO QUÍMICA. II. MÉTODO ANALÍTICO ${ }^{1}$
}

\author{
ADAILSON P. de SOUZA ${ }^{2}$, HÉLIO T. PRATES ${ }^{3}$, FRANCISCO A. FERREIRA ${ }^{4}$, EFRAIM L. REIS ${ }^{5}$ e CLAUDIO P. JORDÃO
}

\section{RESUMO}

Em razão das poucas de informações existente na literatura, sobre a mobilidade do glyphosate e do imazapyr, em solos de baixa atividade, comum em países tropicais, foi conduzido, em laboratório, um estudo sobre a mobilidade vertical desses herbicidas em dois solos com diferentes composições químicas e fisicas. Para estudar essa mobilidade, foram utilizadas colunas de solo com diferentes alturas, as quais, após aplicação dos produtos na dose comercial de $4 \mathrm{~L} \mathrm{ha}^{-1}$, foram submetidas a um regime hídrico de $40 \mathrm{~mm} \mathrm{~h}^{-1}$, por um período de $4 \mathrm{~h}$. As análises dos resíduos nas diferentes profundidades foram feitas utilizando-se os métodos voltamétrico (polarografia) e HPLC, para o glyphosate e imazapyr, respectivamente. Com base nos resultados, foi possível concluir que: a) os métodos voltamétrico, para o glyphosate, e
HPLC, para o imazapyr, são adequados para os estudos de identificação e quantificação de resídu os em água e solo; b) os limites de quantificação dos resíduos foram de $0,4 \mu \mathrm{g} \mathrm{mL}^{-1}$ e $5 \mu \mathrm{g} \mathrm{L}^{-1}$ para o glyphosate e o imazapyr, respectivamente; c) a taxa de recuperação do glyphosate, nas amostras de solo (76 e 78\% para os solos de Viçosa e Sabará, respectivamente) foi menor que na amostra de água (83\%); d) a taxa de recuperação do imazapyr, em águ a e solo, foi próxima de $100 \%$; e) a lixi viação do glyph osate nos solos foi muito baixa; e f) o imazap yr apresento u alta lixiviação, porém difere nciada entre os solos estudados, sendo essa maior no solo de textura franco-are nosa de Viçosa que no de argila de Sabará.

Palavras chave: Herbicidas, voltametria, polarografia, cromatografia, HPLC.

\section{ABSTRACT \\ Glyphosate and imazapyr leaching in soils with different textures and chemical composition. II. Analytical method}

Due to the scarce information available in the literature on the glyphosate and imazapyr mobility in low activity soils, which is common in the tropical countries, a laboratory study was conducted on the vertical mobility of these herbicides in two soils with different physical and chemical compositions. For studying th is mobility, the soil columns with different heights were submitted to a water flux of $40 \mathrm{~mm} \mathrm{~h}^{-1}$ over a $4 \mathrm{~h}$ period after the product applications in a commercial dosage of $4 \mathrm{~L} \mathrm{ha}^{-1}$. The residue analyses at different depths were realized by the voltametric (polarographic) and HPLC methods for glyphosate and imazapyr respectively. Based on the results it was possible to conclude that: a) the voltametric method for gly pho sate and the HPLC for imazapyr are both ade quate for studying the identification and quantification of residues in water and soil; b) the boundaries of residue quantification were

\footnotetext{
${ }^{1}$ Recebido para publicação em 28/05/1998 e na forma revisada em 13/11/1998.

${ }^{2}$ Prof. visitante da UFRR, Campus do Cauame. CEP: 69306-210, Boa Vista/RR.

${ }^{3}$ EMBRAPA/CNPMS. C.P. 151, CEP: 35701-970, Sete Lagoas/MG.

${ }^{4}$ Prof. do Departamento de Fitotecnia da UFV. CEP: $36571-000$, Viçosa/MG.

${ }^{5}$ Prof. do Departamento de Química da UFV. CEP: 36571-000, Viçosa/MG.
} 
$0.4 \mu \mathrm{g} \mathrm{mL} \mathrm{m}^{-1}$ and $5 \mu \mathrm{g} \mathrm{\textrm {L } ^ { - 1 }}$ for glyphosate and imazapyr res pectively; c) the glyphosate recuperation rate in the soil samples (76 and 78\% for Viçosa and Sabará soils, respectively) was lower than in the water sample $(83 \%)$; d) the imazapyr recuperation rate in water and soil was about $100 \%$; e) the glyphosate leaching in the

\section{INTRODUÇÃO}

A introdução de moléculas orgânicas com características herbicidas, a partir da década de 40, para o controle das plantas daninhas, tem permitido reduções significativas nos custos de produção e aumento na produtividade das culturas. Entretanto, a preocupação com o destino dessas moléculas liberadas no ambiente tem sido objeto de muitas pesquisas.

O movimento descendente dessas moléculas, no perfil do solo, talvez seja um dos processos que mais tem chamado a atenção da sociedade, em razão da possibilidade de contamin ação do le nçol freático, uma das principais fontes de abastecimento dos reservatórios de água para o consumo humano e animal.

O glyphosate é um herbicida aplicado em pós-emergência, não-seletivo, de amplo espectro e com atividade sistêmica na planta (Carlisle e Trevors, 1988). Estudos sobre o comportamento do glyphosate no ambiente têm demonstrado que este é rapidamente inativado quando em contato com o solo (Sprankle et al., 1975a; Torstensson e Aamisepp, 1977; Glass, 1987; New ton et al., 1994; Gerritse et al., 1996). A baixa atividade do glyphosate no solo é proveniente das fortes ligações dessa molécula com os constituintes do solo. Tais ligações ocorrem por competição com os fosfatos inorgânicos, pelos sítios de ligação do solo (Hance, 1976; Moshier e Penner, 1978); pela formação de complexos glyphosate-cátions polivalentes-argila (McConnell e Hossner, 1985); pela interação com substân cias húmicas (Piccolo et al., 1996) e pela formação de complexos metálicos insolúveis na solução do solo studied soils was very low; f) the imazapyr presented high leaching although differentiate between the studied soils being higher in the sandy loam texture soil of Viçosa than in the one of clay in Sabará.

Key words: Herbicides, voltametric, polarography, chromatography, HPLC.

(Subramaniam e Hoggard, 1988). A elevada afinidade do glyphosate por esses sítios de ligação tem justificado em muitos trabalhos a sua baixa mobilidade, levando a conclusões de que o mesmo é muito pouco lixivi ado (Sprankle et al., 1975b; Roy et al., 1989; Sánchez-Martin et al., 1994; Cheah et al., 1997). Entretanto, outras pesquisas conduzidas sob condições mais favoráveis (solos arenosos, baixo conteúdo de óxidos de $\mathrm{Fe}$ e $\mathrm{Al}$ ), têm demonstrado uma lixiviação signi fic ativa desse herbicida para as camadas mais inferiores do solo (Damanakis, 1976; Piccolo et al., 1994).

O imazapyr é um dos herbicidas mais representativos do grupo das imidazolinonas, de amplo espectro no controle de plantas daninhas anuais e perenes, podendo ser aplic ado em pré e em pós-emergência (Lee et al., 1991). A atividade bi ológi ca e o seu movi mento no solo são grandemente influenciados por numerosos fatores ambientais. Dentre esses fat ores, tem-se demonstrado que a textura, o tipo de argila, a umidade e o $\mathrm{pH}$ influenciam dire tamente a adsorção e, conseqüentemente, a mobilidade do imazapyr no perfil do solo (Mi chael e Neary, 1993; Ismail e Ahmad, 1994). Wehtje et al. (1987) observaram maior mobilidade do imazapyr em solos argilosos e, também, que essa mobilidade diminuiu com a redução da umida de e do pH do solo. Entretanto, resultados contrários foram observados por Vizantinopoulos e Lolos (1994), que encontraram maior mobilidade no solo com menor teor de argila. Essa diferença de mobilidade pode estar relacionada a fatores que estariam agindo sobre os fenômenos adsortivos, como as características mineralógicas e o teor e o tipo de matéria orgânica dos solos estudados. Pusino et al. (1997) constatar am que a adsorção do imazapyr é fortemente influenciada pelo $\mathrm{pH}$ e 
pela carga do componente adsorvente e que, a presença de óxidos de ferro amorfo e matéria orgânica, a $\mathrm{pH}<5$, é efetiva na sua rete nção. $\mathrm{O}$ ou tro fe nômeno ainda pouco es tudado é a formação de complexos metálicos que poderiam promover maior ou menor in te raçã o com a superfície das argilas. Duda et al. (1996), em estudos sobre a formação de complexos $\mathrm{Cu}$ (II)imazapyr, observaram que esse comple xo age como molécula quelante, sendo efetivo sobre uma extensa faixa de $\mathrm{pH}$.

Em razão da grande variabilidade de resposta apresentada por esses produtos, quando aplicados a distint os solos, e das poucas informações encontradas na literatura, sobre o comportamento dessas moléculas em solos tropicais, desenvolveu-se o presente trabalho, com o objetivo de avaliar, at ra vés de métodos analíticos, a mobilidade vertical do glyphos ate e do imazapyr em solos de diferentes texturas e composição química.

\section{MATERIAL E MÉTODOS}

Amostras de solo provenientes das subestações da CEMIG, dos municípios de Viçosa e Sabará em Minas Gerais, foram coletadas na camada superficial (de 0 a $20 \mathrm{~cm}$ ), secas ao ar e passadas em peneiras de 4,0 e 2,0 $\mathrm{mm}$ de abertura de malha, para os ensaios de lixiviação e caracterização química, física e mineralógica, respectivamente (Tabela 1).

Foram utilizados os herbicidas glyphosate e imazapyr (Figura 1), que são inibidores da síntese de aminoácidos aromáticos (fenilalanina, tirosina e triptofan) e de cadeia ramificada (valina, leucina e isoleucina), respectivamente.

Para estudar o movimento dos herbici das no solo, foram utilizados anéis de tubos de PVC com 1,0 e $5,0 \mathrm{~cm}$ de altura e $9,8 \mathrm{~cm}$ de diâmetro interno. As colunas com as alturas de 1,0 e $30 \mathrm{~cm}$, formadas pela ju nção dos ané is, ti veram suas paredes internas previamente parafinadas, antes de receberem o solo, a fim de promover a formação de uma camada hidrofóbica, evitando-se, assim, a possível formação de um fluxo de águ a pelas paredes das colunas. Na parte inferior das colunas for am colocados discos de pa pel-fil tro de filtragem rápida (INLAB - $\mathrm{n}^{\mathrm{o}} 10$ - porosidade de $10 \mu \mathrm{m})$, de $11 \mathrm{~cm}$ de diâmetro e uma malha de gaze (abertura de malha de $1,0 \mathrm{~mm}$ ), presa por elástico, objetivando reter o solo na coluna, deixando, entretanto, passagem para o lixiviado (Figura 2).

TABELA 1. Composição química, fisica e mineralógica das amostras dos solos.

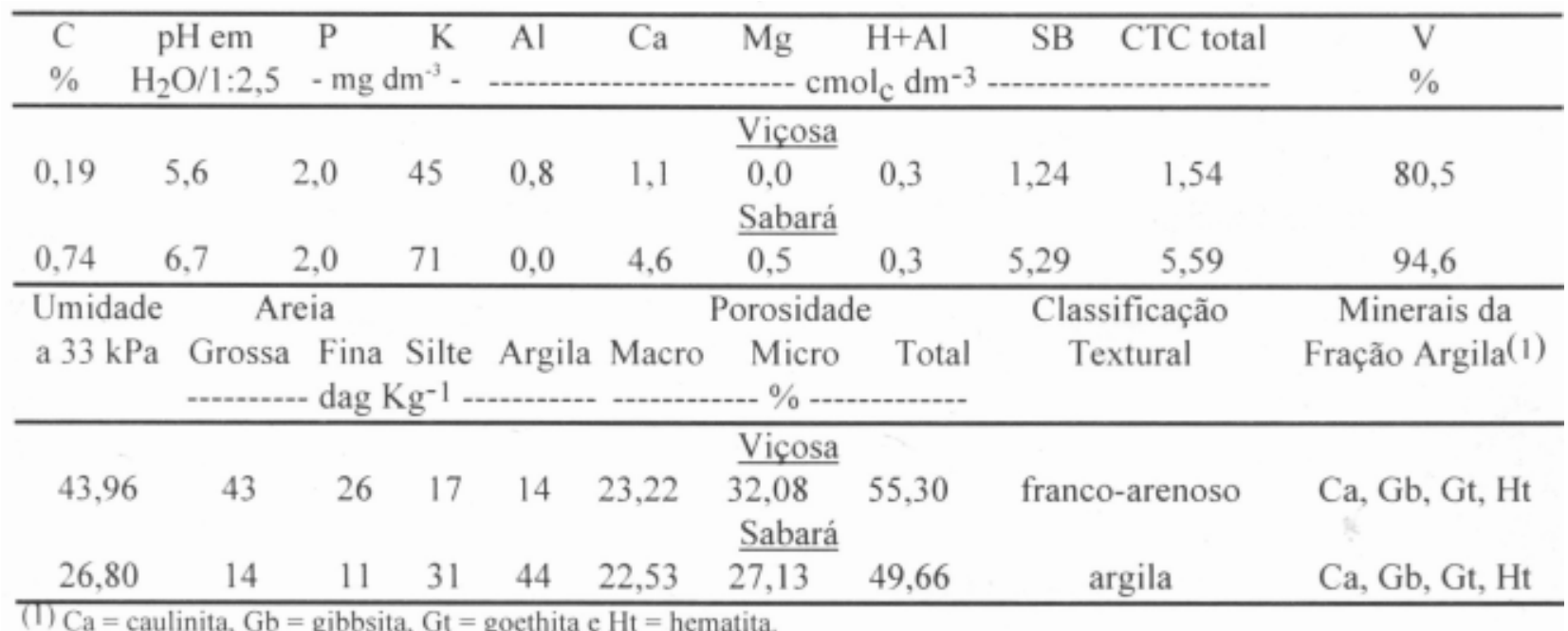


<smiles>CC(C)[NH2+][O+]P([NH3+])(=O)CNCC(=O)O</smiles>

Sal de isopropilamina de $\mathrm{N}$-(fosfonometil)-glicina

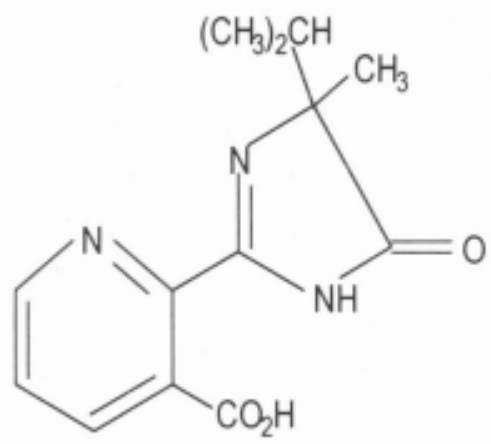

cido 2-(4-isopropil-4-metil-5-oxo-2-imidazolina-2-ilo) nicotinico
- nome comercial: Roundup S.Aq.C.

- grupo químico: aminoácido fosfanado

- categoria iônica: herbicida anfótero

- peso molecular: 228,2

- pressão de vapor: desprezível

- solubilidade em água: 12.000 mg L-1, a

$25^{\circ} \mathrm{C}$

- nome comercial: Arsenal 250 S.Aq.C.

- grupo químico: Imidazolinonas

- categoria iônica: ácido

- peso molecular: 261,3

- pressão de vapor: < 1 x 10-7mmHg, a $60^{\circ} \mathrm{C}$

- solubilidade em água: $11.272 \mathrm{mg} \mathrm{L-1}$, a $25^{\circ} \mathrm{C}$

FIGURA 1. Principais características do glyphosate (a) e do imazapyr (b).
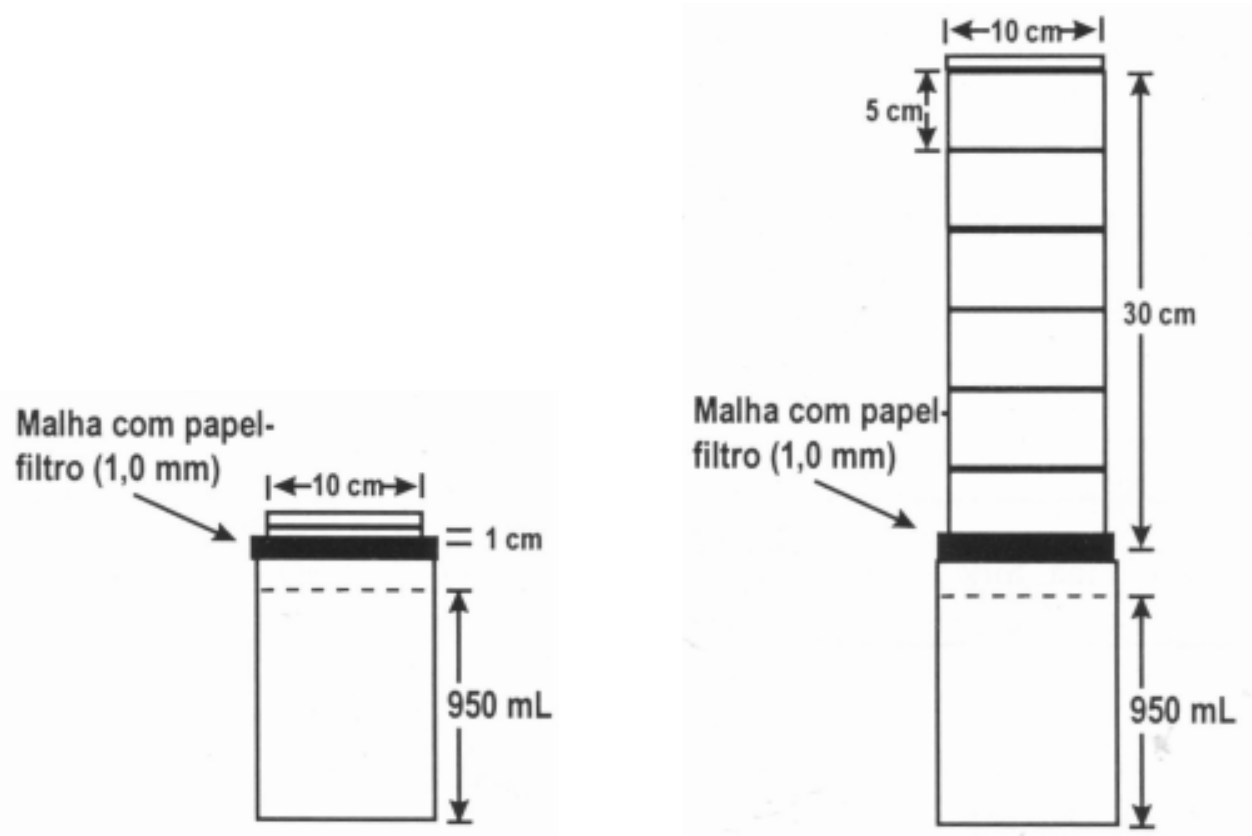

FIGURA 2. Representação esquemática das colu nas usadas no estudo da lixi viação dos herbicidas glyphosate $(1,0 \mathrm{~cm})$ e imazapyr $(30 \mathrm{~cm})$. 
Nas colunas, foram colocados os solos em quantidade suficiente para alcançar a altura desejada $(1,0$ e $30 \mathrm{~cm})$ e levados para uma mesa vibratória até ser obtida uma densidade aparente de $1,2( \pm 0,1) \mathrm{g} \mathrm{cm-}^{3}$. Em se guida, as col unas contendo os materiais de solo foram colocadas em bandejas com água destilada, durante um período suficiente para que houvesse a saturação por capilaridade. Após esse período, o excesso de água foi drenado, colocando-se as colunas sobre béqueres por um período de 24 a $48 \mathrm{~h}$, tempo suficiente para que a umidade do solo ficasse próximo à capacidade de campo $(33 \mathrm{kPa})$. Em se guida, fez-se a ap li ca çã o do he rbicida, uniformemente, por meio de uma mic ropulverização. A quantidade de herbicida aplicado correspondeu à dose de $4 \mathrm{~L}$ ha ${ }^{\mathrm{I}}{ }^{\mathrm{d}}$ do produto comercial Roundup e Arsenal (480 g L-1 de glyphosate e 266,3 $\mathrm{g} \mathrm{L}-^{1}$ de imazapyr, respectivamente) em uma calda de 400 L. Após a ap li ca ção dos produtos, as coluna s for am colocadas sobre recipientes de captação e levadas para um si mulad or de chuva, onde for am submetidas a um regime hídrico de $40 \mathrm{~mm} \mathrm{~h}^{-}{ }^{\mathrm{I}}$ por um período de quatro horas, com o simulador sendo desligado a cada $30 \mathrm{~min}$, por $5 \mathrm{~min}$, até a obtenção de um volume de $950 \mathrm{~mL}$ de lixi viado por coluna.

Após a coleta do lixiviado, as colunas foram secionadas nas junções dos anéis, foi retirado o solo, pesado e homogeneizado, para, em seguida, serem coletados $50 \mathrm{~g}$ em cada seção. As amostras de solo e de lixiviado foram submetidas aos procedimentos de extração e quantificação dos herbicidas, segundo a metodologia adotada para cada produto.

\section{Determinação do glyphosate em amostras de água e solo}

A determinação do glyphosate foi realizada no laboratório de eletroanalítica do Departamento de Química da Universidade Federal de Viçosa, MG, pela técnica voltamétrica, utilizando-se a metodologia adaptada de Friestad e Bronstad (1985).
Aparelhagem: Foi utilizado o polarógrafo da EG\&G Princeton Applied Reseach, modelo 384B, conectado a um sistema de 3 eletrodos (Figura 3). 0 eletrodo de trabalho empreg ado foi em eletrodo de mercúrio de gota estática (SMDE). $O$ eletrodo auxiliar utilizado consistiu de um fio de platina, sendo o de referência um eletrodo de $\mathrm{Ag} / \mathrm{AgCI}$, is olado da solução por uma ponte salina. A cela de eletrólise apresenta capacidade de $20 \mathrm{~mL}$ (Figura 3). A coluna cromatográfica foi um tubo de $300 \mathrm{~mm}$ de comprimento por $20 \mathrm{~mm}$ de diâmetro interno com disco-fil tro de vidro e uma torneira de teflon.

Reagentes: Padrão analítico do glyphosate, grau analítico (99\%); resina trocadora de cátion, DOWEX 50WX8-200, 100-200 mesh, forma clorada; soluções de ácido clorídrico $1 \mathrm{M}$; hidróxido de potássio $1 \mathrm{M}$; ácido sulfúrico $50 \% \mathrm{~m} / \mathrm{v}$; nitrito de sódio $0,2 \mathrm{M}$; sulfamato de amônio, $1 \mathrm{M}$. Os reagentes utilizados foram todos da Merck.

Preparo das soluções: a) solução estoque de $20 \mu \mathrm{g} \mathrm{mL-}{ }^{1}$ : foram dissolvidos, por aquecimento em banho-maria, $2 \mathrm{mg}$ de glyphosate em $100 \mathrm{~mL}$ de água contendo 10 gotas de solução de ácido sulfúrico $50 \%$. A solução é estável por pelo menos três meses, à temperatura ambiente. b) solução fortificada: com a solução esto que $\left(20 \mu \mathrm{g} \mathrm{mL}^{1}\right)$, for am reti radas alíquotas de 0,$5 ; 1,0 ; 1,5 ; 2,0 ; 2,5$ e $5,0 \mathrm{~mL}$ e transferidas para balões de $25 \mathrm{~mL}$, completando-se os volumes com HCI 1M, obtendo-se a curva-padrão com as concen traçõe s de 0,$4 ; 0,8 ; 1,2 ; 1,6 ; 2,0$ e 4,0 $\mathrm{g} \mathrm{mL-}{ }^{1}$. Para determinar a taxa de recuperação em água e solo foram retiradas

alíquotas de $5 \mathrm{~mL}$ da solução estoque $\left(20 \mu \mathrm{g} \mathrm{mL}^{-}\right)$e transferidos para frascos contendo amostras de água e solo, obtendo-se uma concentração final de $2 \mu \mathrm{g} \mathrm{mL}-1$.

Extração: a) solo: após pesados $50 \mathrm{~g}$ de solo da coluna de $1,0 \mathrm{~cm}$, o mesmo foi coloc ado no recipiente do agitador mecânico (capacidade de $500 \mathrm{~mL}$ ) e adicionaram-se $100 \mathrm{~mL}$ de solução de $\mathrm{KOH}$ 0,5 M. O mesmo foi fechado com rolha de borracha e agitado por $15 \mathrm{~min}$, Removeu-se a rolha de borracha e colocou-se em centrífuga, a $2.000 \mathrm{rpm}$ por $15 \mathrm{~min}$, em seguida, transferiu-se o 
sobrenadante para um balão de $500 \mathrm{~mL}$. Acrescentaram-se outros $100 \mathrm{~mL}$ de solução de $\mathrm{KOH}$ 0,5 M ao recipiente da centrífuga, repetindose o procedimento de agitação e centrifugação. $\mathrm{O}$ sobrenadante foi transferido ao frasco contendo a solução da primeira extração. Completou-se o volume do balão volumétrico de $500 \mathrm{~mL}$ com água deionizada. b) água: filtraram-se $500 \mathrm{~mL}$ da amostra em papel-fil tro (Whatman - fil tra gem rápida) e ajustou-se o $\mathrm{pH}$ entre 10 a 11 com solução de $\mathrm{KOH} 1 \mathrm{M}$.

\section{Aparato}

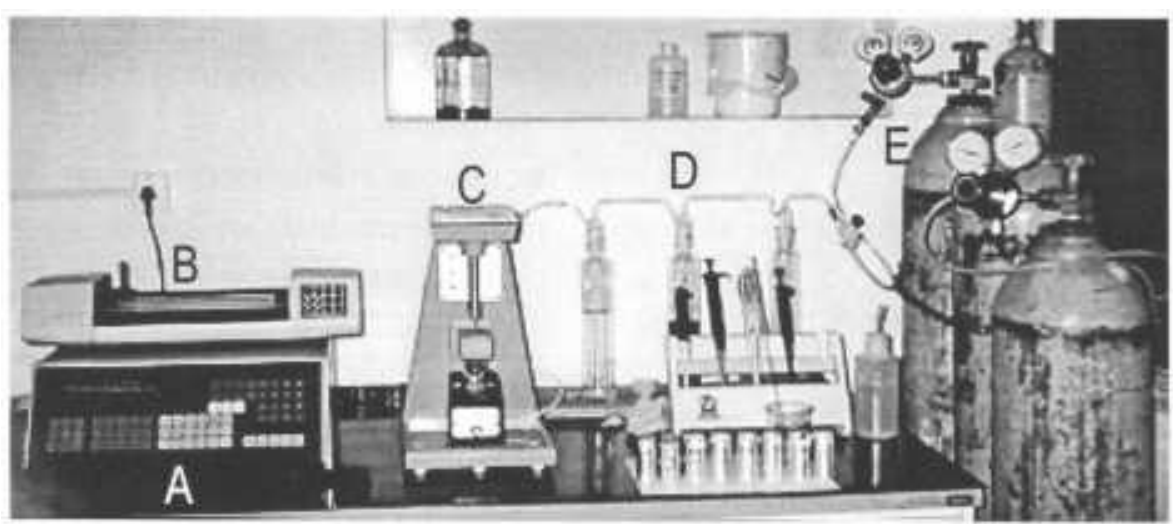

\section{Cela polarográfica}

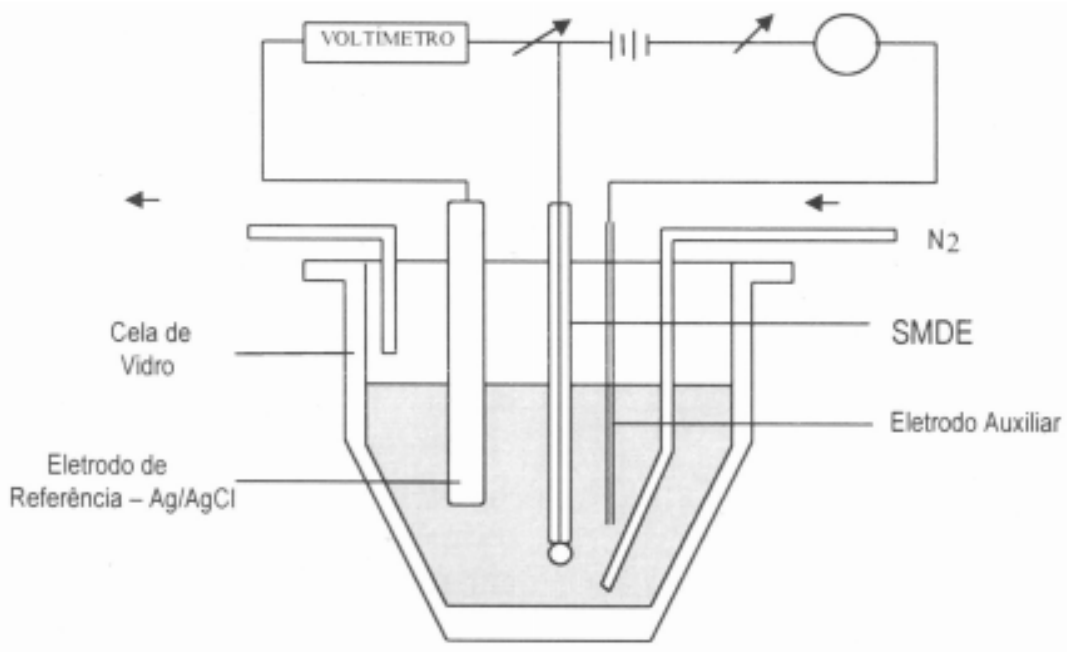

FIG URA 3. Sis tema voltamétrico (acima): Pol aró gra fo EG\&G P.A.R. mode lo 384B (A), "plotter" digital (B), eletrodo gotejante de mercúrio estático modelo 303A (C), sistema de purificação (D), cilindros de $\mathrm{N}_{2}$ (E). Esque ma da cela polarográfica (abaixo): Eletrodo gotejante de mercúrio (SMDE), eletrodo $\mathrm{Ag} / \mathrm{AgCI}$.

Troca aniônica: Preparou-se a coluna cromatográfica, completando-a com $20 \mathrm{~mL}$ da resina DOWEX 50WX8 - 200. Lavou-se a resina com água deionizada, até alcançar de 4 a $5 \mathrm{~cm}$ de al tura acima do disco-filtro da coluna. Para prevenir o remoinho da resina foi pressionado um chumaço de lã de vidro sobre a superfície da resina. Próximo ao dia da análise, adicionaram-se 
as amostras de água e extrato de solo na coluna. Ajustou-se o fluxo ao máximo de 2 gotas s- ${ }^{1}$, até a passagem de toda a amostra $(500 \mathrm{~mL})$. Em seguida, lavou-se a coluna com $50 \mathrm{~mL}$ de solução de $\mathrm{KOH}$ 0,25 M e, após drenagem, com $50 \mathrm{~mL}$ de água deionizada. O percolado das amostras, do $\mathrm{KOH}$ e da água deionizada foi descartado. Em seguida, adaptou-se um frasco de $50 \mathrm{~mL}$ de capacidade contendo $10 \mathrm{~mL}$ de solução de HCI 5 M sob a saída da coluna. Com fluxo $\square 0,5$ gota/s, eluiu-se a coluna com $40 \mathrm{~mL}$ de solução de HCI $0,1 \mathrm{M}$. Transferiu-se $25 \mathrm{~mL}$ do filtrado para frasco de vidro escuro, com tampa de rosca, o restante foi guardado para possível aferição. Em todas as etapas de passagem do eluado na coluna, teve-se o cu idado de não de ix ar o meni sco atingir a superfície da resina.

Nitrosação: Para as porções de $25 \mathrm{~mL}$ das amostras e padrão, adicionou-se $1 \mathrm{~mL}$ da solução de nitrito de sódio agitou-se por $5 \mathrm{~s}$ e deixaram-se os frascos em repouso por $15 \mathrm{~min}$. Em seguida, o excesso de nitrito foi destruído pela adição de $1 \mathrm{~mL}$ da solução de sulfamato de amônio. O derivativo nitrosado (Figura 4) é estável por até 10 dias, à temperatura ambiente.

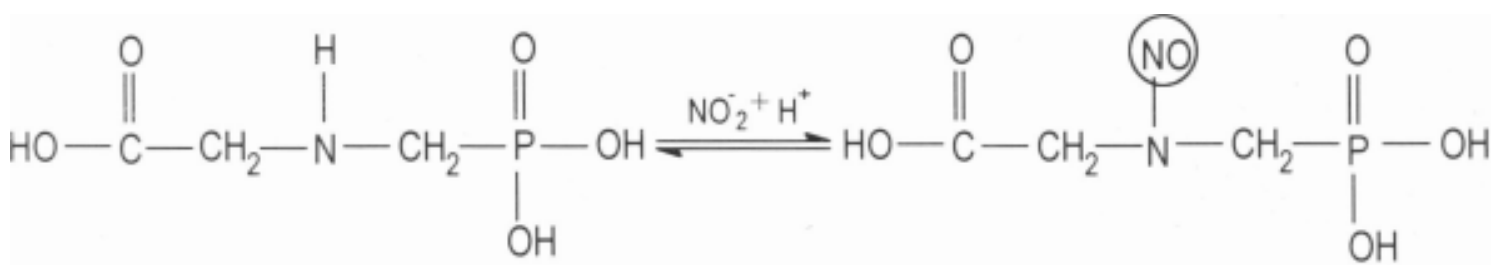

Glyphosate

Derivativo Nitrosado

FIGURA 4. Reação de nitrosação do glyphosate para determinação voltamétrica.

Determina ção voltamét rica: Colocaramse $10 \mathrm{~mL}$ de HCI $1 \mathrm{M}$ dentro da cela polarográfica. Desoxigenou-se o sistema, borbulhando nitrogênio puro através da cela por pelo menos 4 min. Após a remoção do oxigênio, deu-se inicio à medição usando-se a técnica voltamétrica de onda quadrada sob as seguintes condições: inicio da varredura a $-0,5 \mathrm{~V}$; final da varredura a $-0,9 \mathrm{~V}$; velocidade de varredura de $2 \mathrm{mV} \mathrm{s}^{-}{ }^{1}$ na direção negativa; amplitude do pulso de $100 \mathrm{mV}$; tempo de purga de $240 \mathrm{~s}$. Esse procedimento foi repetido, usando-se a amostra nitros ada corres pon dente. Todas as amostras foram realizadas em triplicata.

\section{Determinação do imazapyr em amostras de água e solo}

A determinação do imazapyr foi realizada no laboratório de Agroquímica da EMBRAPA/Milho e Sorgo, em Sete Lagoas, MG, utilizando-se, com algumas modificações, a técnica da cromatografia líquida de alta eficiência (HPLC) descrita por Liu et al. (1992).

Apar elhagem: Cromatógrafo líquido de alta eficiência, marca Shimadzu, modelo LC 10A, ad ap tado com bo mba LC-1OAD, in je tor de amostra com válvula modelo Reodyne com "loop" de $100 \mu \mathrm{L}$, pré-coluna marca Shimadzu, modelo Shim-Pack G-ODS(4), com diâmetro interno de $4 \mathrm{~mm} \times 1 \mathrm{~cm}$ de comprimento e coluna marca Shi mad zu modelo Shim-Pack CLC-ODS (M), com diâmetro de $4,6 \mathrm{~mm}$ x $25 \mathrm{~cm}$ de comprimento, em aço inox, com partículas de $5 \mu \mathrm{m}$ de diâmetro de poro. Todo o sistema foi controlado pelo "software" Class-LC 10A, através do controlador, modelo CBM-10A.

Balança analítica Mettler, modelo H-18 ( \pm 0,1 mg); rotavapor Büchi HB-140 com balão de $50 \mathrm{~mL}$; microssering a de $50 \mu \mathrm{L}$, marca SGE Scientifica PtY. Ltda.; papel filtro Whatman quantitativo n2 5 , com $5,5 \mathrm{~cm}$ de diâmetro; filtro para amostras tipo Millex, com diâmetro de poro 
de $0,22 \mu \mathrm{m}$; membranas filtrantes MilliporeMillex HV, com diâmetro de poro de $0,45 \mu \mathrm{m}$.

Reagentes: Padrão analítico do imazapyr, grau analítico; metanol e acetonitrila com pureza para HPLC. Água para HPLC, purificada pelo sistema Milli-Q da Millipore. Ácido acético gl ac ia l; hi dróx id o de sódio, 0,5 M; ácido clorídrico $6 \mathrm{M}$; diclorometano e acetato de chumbo a $10 \% \mathrm{~m} / \mathrm{v}$.

Fortificação da água e do solo: a) soluçãoestoque: foram dissolvidos $10 \mathrm{mg}$ de imazapyr em $100 \mathrm{~mL}$ de metanol $(100 \mu \mathrm{g} \mathrm{mL}-1)$. A partir dessa solução, foi retirada uma alíquota de 0,1 $\mathrm{mL}$ e transferida para um balão de $10 \mathrm{~mL}$, completando-se em seguida o volume com água purificada (1 $\left.\mu \mathrm{g} \mathrm{mL}^{-1}\right)$; b) solução fortificada para amostra de água (curva-padrão em água): da solução-estoque $\left(1 \mu \mathrm{g} \mathrm{mL}-{ }^{1}\right)$, foram retiradas alíquotas de 0,$05 ; 0,1 ; 0,2 ; 0,4 ; 0,8$ e $1,6 \mathrm{~mL}$ e transferid as para balões de $10 \mathrm{~mL}$, completandose os volumes com água purificada e outra bateria em água de torneira, obtendo-se a curva com as concentrações de 5, 10, 20, 40, 80 e $160 \mu \mathrm{g} \mathrm{L}^{-}$; c) solução fortificada para amostra de solo (curva padrão no solo): da solução-estoque $\left(100 \mu \mathrm{g} \mathrm{mL}^{-1}\right)$, foram retiradas alíquotas de 0,025 ; 0,$05 ; 0,1 ; 0,2 ; 0,4$ e $0,8 \mathrm{~mL}$ e transferidas para balões de $10 \mathrm{~mL}$, completando-se os volumes com água purificada, obtendo-se as concentrações de 250, 500, 1000, 2000, 4000 e 8000 g L- $^{1}$. Dessas soluções, foram reti-radas alíquotas de $5 \mathrm{~mL}$ e transferidas para tubos de centrífuga, contendo $5 \mathrm{~g}$ de solo. A taxa de recuperação em água e solo foi obtida com alíquotas de $5 \mathrm{~mL}$ da soluçãoestoque $\left(1 \mathrm{~g} \mathrm{~mL}^{-1}\right)$, sendo a solução transferida para frascos conten do $5 \mathrm{~g}$ das amostras, obtendose uma concentração final de $1 \mu \mathrm{g} \mathrm{mL}-1$.

Extração: Para as amostras de água, o processo constou apenas de uma filtragem em filtro tipo Millex. Para as amostras de solo, adotou-se o seguinte procedimento (Figura 5):

- Pesaram-se 5 g de solo, diretamente na cubeta da centrífuga;

- Adicionaram-se $15 \mathrm{~mL}$ de uma solução de $\mathrm{NaOH}$ $0,7 \mathrm{M}$, para efetuar a extração;

- Agitaram-se as amostras por $15 \mathrm{~min}$;
- Centrifugaram-se as mesmas a $3.000 \mathrm{rpm}$, durante $15 \mathrm{~min}$;

- Transferiram-se $10 \mathrm{~mL}$ do sobrenadante para um becker;

- Ajustou-se o pH para 7,5 com HCI $6 \mathrm{M}$;

- Adicionou-se 0,5 mL de acetato de chumbo a $10 \%$;

- Agitou-se por $1 \mathrm{~min}$;

- Tornou-se a centrifugar a $3.000 \mathrm{rpm}$, por 15 $\min$;

- Transferiu-se o sobrenadante para um béquer;

- Ajustou-se o pH para 2,5 com HC1 $6 \mathrm{M}$;

- Levou-se o sobrenadante para um funil de partição;

- Fez-se a partição com diclorometano (3 x de 10 $\mathrm{mL}$ );

- Recolheu-se a fração orgânica em balão do rotavapor;

- Levou-se à secura no rotavapor à temperatura de $35^{\circ} \mathrm{C}$;

- Retomou-se a amostra com $5 \mathrm{~mL}$ da fase móvel;

- Filtrou-se e injetou-se imediatamente no HPLC.

Fase móvel para o HPLC: Preparou-se uma solução contendo a seguinte mistura: $90 \mathrm{~mL}$ de acetonitrila, $660 \mathrm{~mL}$ de água para HPLC purificada, $10 \mathrm{~mL}$ de ácido acético e $240 \mathrm{~mL}$ de metanol. Em seguida, a solução foi filtrada em um conjunto de papel-filtro e membrana filtrante sob vácuo.

Condições de análise do HPLC: Tanto para as curvas-padrão, quanto para as amostras de água e de solo, as condições do HPLC foram: temperatura da coluna: $40^{\circ} \mathrm{C}$; pres são da s bombas: $155 \mathrm{psi}$; fluxo da fase móvel: I $\mathrm{mL}$ min1; lâmpad a do de tect or UV -VIS : deutério; comprimento de onda (X) do detetor: $240 \mathrm{~nm}$; tempo de retenção: $10 \mathrm{~min}$; fase móvel:

acetonitrila: água: ácido acético: metanol (90:660:10:240).

Quantificação: Para a quantificação do resíduo do imazapyr nas amostras de água e solo, foi utilizada a técnica de estimativa da concentração $\left(\mu \mathrm{g} \mathrm{L}^{-1}\right)$, com base nas respostas 
obtid as com o padrão an alítico, na curvapadrão, em água purificada, após ajuste dos dados da resposta do detector do HPLC (altura), em função das doses do imazapyr
( $\mu \mathrm{g} \mathrm{L}^{1}{ }^{1}$ ), a um modelo de regressão linear, pe lo mé to do da mi ni mi zação da so ma dos quadrado dos des vios (Mulholland e Hibbert, 1997).
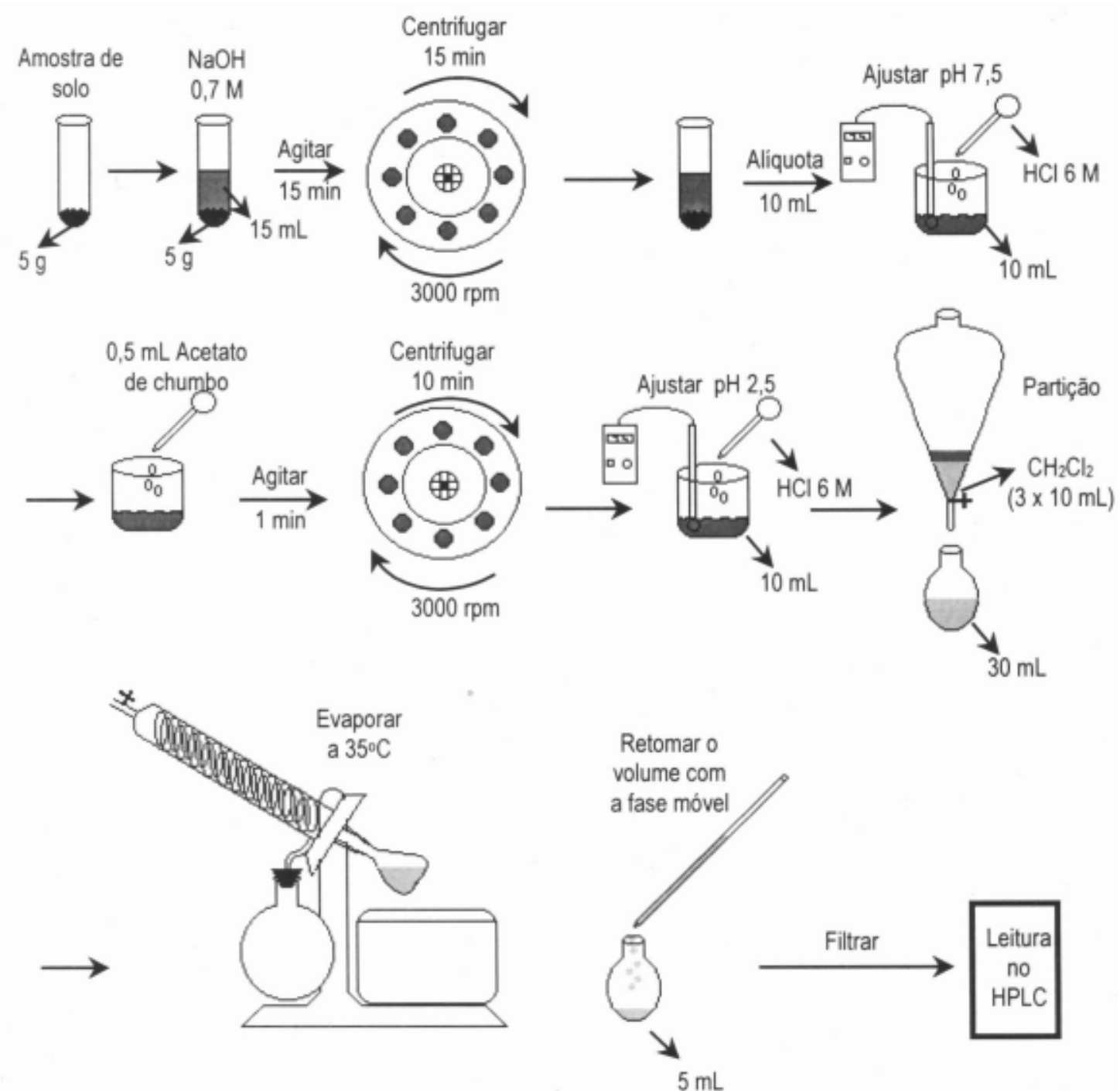

FIGURA 5. Representação esquemática dos procedimentos para extração do imazapyr em amostra de solo.

\section{RESULTADOS E DISCUSSÃO}

Observa-se, pela Figura 6, que o glyphosate nitrosado apresenta curva corrente/potencial bem definida, com um pico obtido no potencial de $-0,76 \pm 0,02 \mathrm{~V}$. A ausência de um pico no tratamento branco $\left(\mathrm{HCI}+\mathrm{NaNO}_{2}\right)$ indica que a purga com N2 por $240 \mathrm{~s}$ e a adição de
$1,0 \mathrm{~mL}$ de sulfamato de amônio foram suficientes para a remoção do oxigênio e do excesso de nitrito das amostras, respectivamente.

A curva de calibração (Figura 7), obtida mediante ajuste de uma função de regressão à resposta do polarógrafo (Corrente, nA) em so lu çõ es com diferent es concen trações do derivativo nitrosado do glyphosate (Figura 6), 
indica um comportamento linear com elevada qualidade de ajuste $\left(\mathrm{r}^{2}=0,9988\right)$. Tais resultados asseguram boa confiabilidade na identificação e quantificação de resíduos de glyphosate com o prime iro ponto da curva de calib ração sendo de $0,4 \mu \mathrm{g} \mathrm{mL}-{ }^{1}$. Se gundo Bronstad e Friestad (1976) e Friestad e Bronstad (1985), o método voltamétrico é de realização rápida e aplicável a um amplo espectro de amostras, cujo li mite inferior de de te cção considerado é aquele em que a menor concentração do derivativo nitrosado seja capaz de formar um pico de corrente em função do potencial, bem definida.

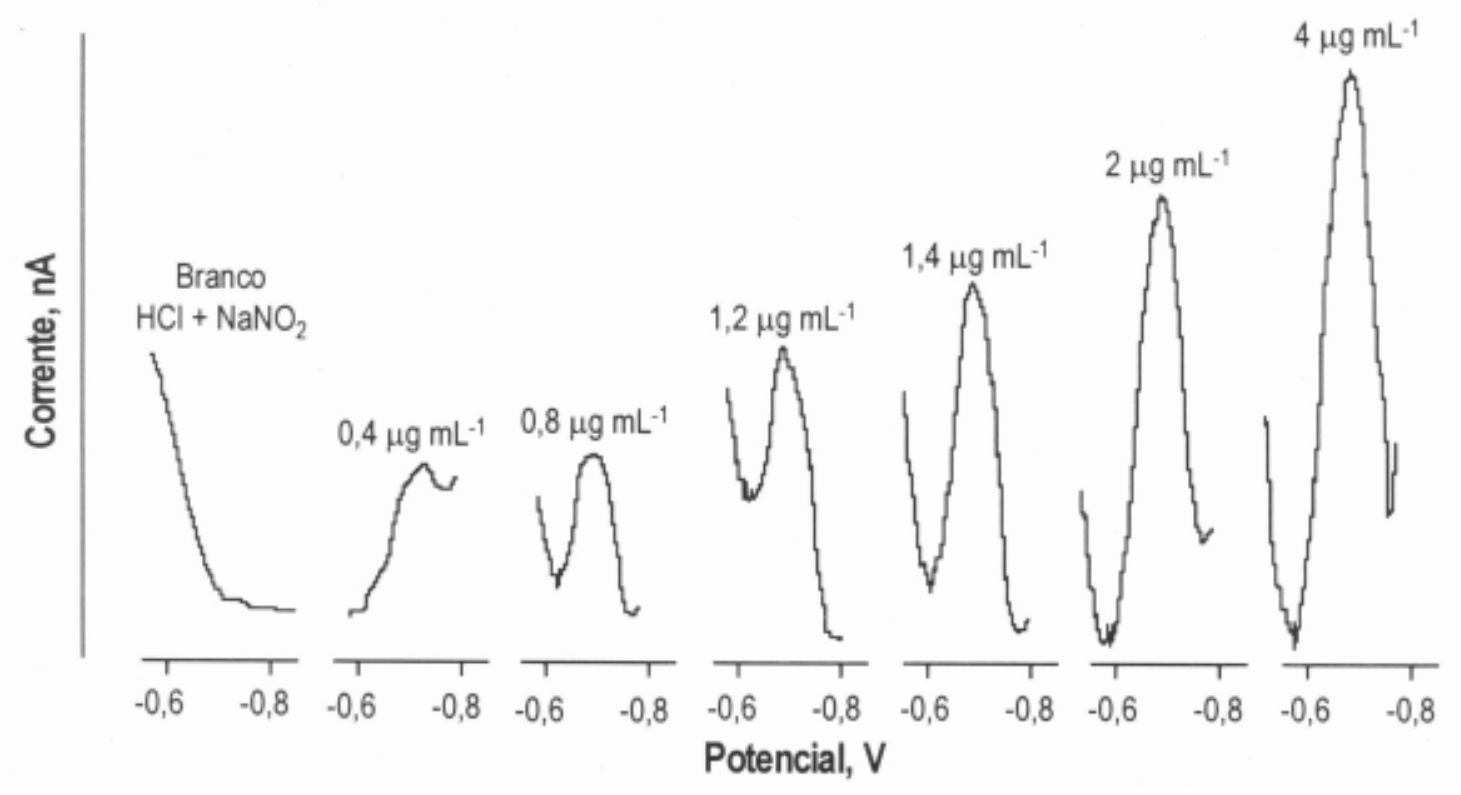

FIGURA 6. Voltamogramas de soluções com diferentes concentrações do glyphosate.

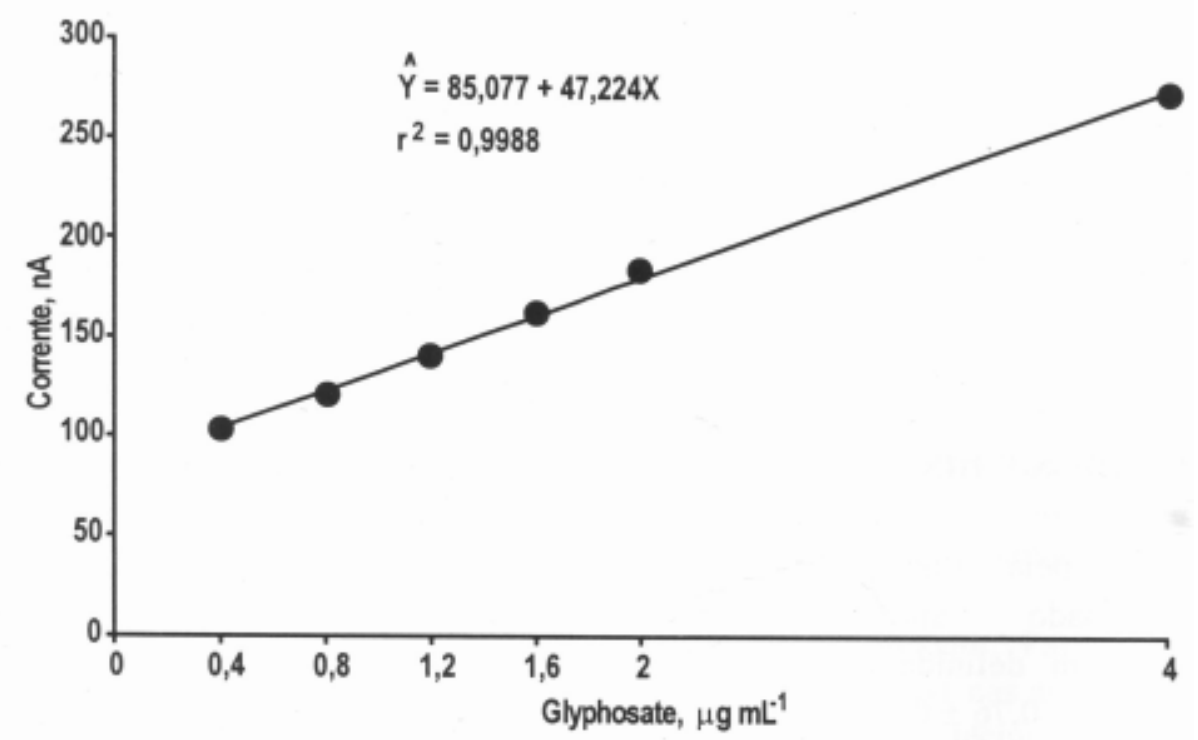

FIGURA 7. Curva de calibração em água obtida por doses crescentes do glyphosate. 
Os dados da Figura 8 mostram a taxa de recuperação, em percentagem, do glyph osate em amostras de água e solo fortificadas com $2 \mu \mathrm{g} \mathrm{mL}-{ }^{1}$ da solução-padrão. A recuperação nas amostras de solo mostraram-se similares (76 e 78\% para os solos de Viçosa e Sabará, respectivamente), sendo estas menores que a amostra de água (83\%). A menor recuperação observada nas amostras de solo é atribuída a adsorção do glyphosate aos constituintes do solo. Segundo Glass (1983 e 1987), em estudos sobre a adsorção do glyphosate pelo solo, foi obse rvada uma rápida adsorção des sa molécu la às várias frações de argila e matéria orgânica.

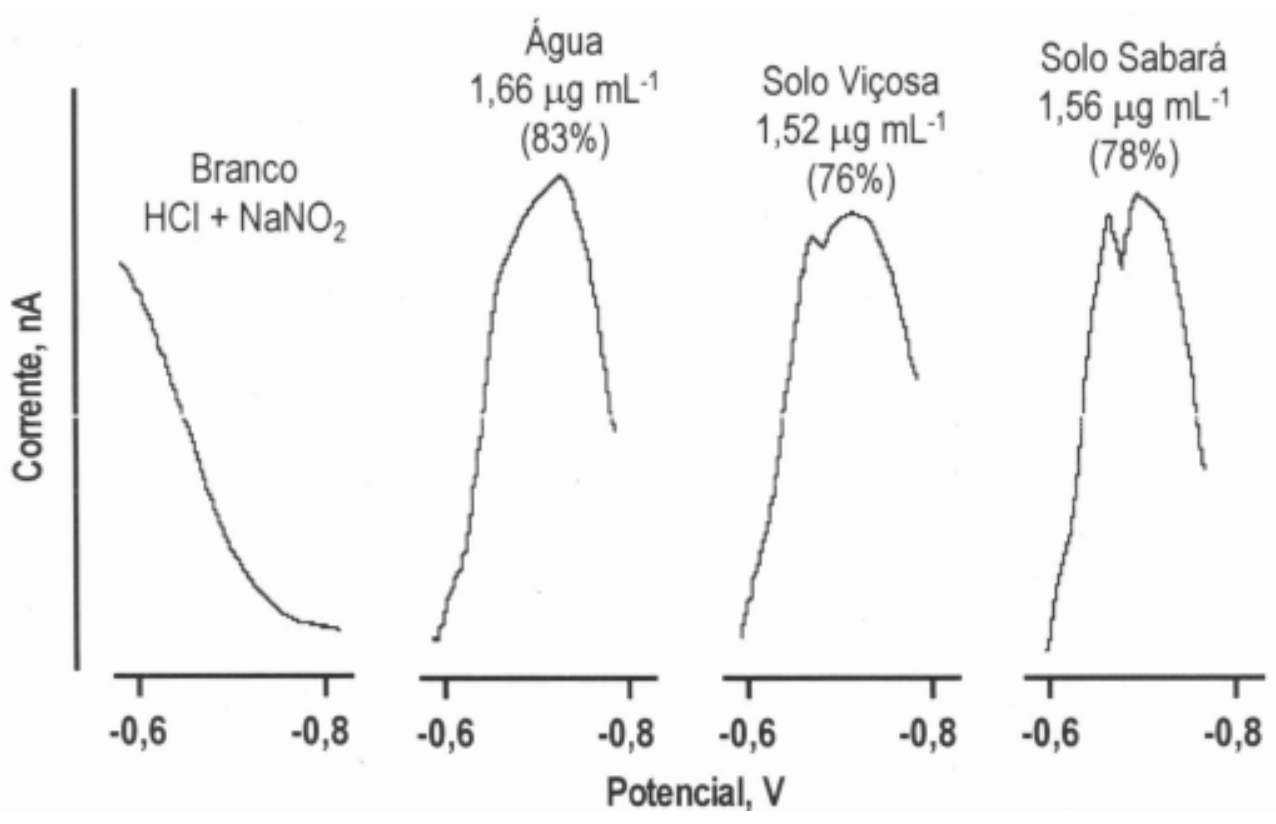

FIGURA 8. Voltamogramas do glyphos ate extraídos de amostras de água e solo, fortificados com $2 \mathrm{~g}$ $\mathrm{mL}^{-1}$ da solução padrão do glyphosate, e suas respectivas concentrações e percentagens de recuperação.

A concentração do glyphosate nas amostras de solo e no lixiviado da coluna de $1 \mathrm{~cm}$ são apresentados na Figura 9. Observa-se, por es ses resul tados, elevad a re te nção de ss as molécul as no solo, cuja concentração na camada de $1 \mathrm{~cm}$ foi de 11,2 e $9,14 \mu \mathrm{g} \mathrm{mL}^{-1}$, para os solos de Viçosa e de Sabará, respectivamente. Tais concentrações representam mais de $50 \%$ do produto aplicado na superfície do solo. Essa elevada capacidade do glyphosate ser adsorvido pelo solo, é explicada em parte, pelo seu caráter anfótero (Figura 1), resultando em sua baixa mobilidade, o que justifica as baixas concentrações no lixiviado $(0,47$ e $0,36 \mu \mathrm{g} \mathrm{mL}-1$, para Viçosa e Sabará, respectivamente). Resultados semelhantes foram obtidos por
Bowmer (1982), em estudos sobre a dissipação do glyphosate em canais de irrigação.

Se gu ndo Sprankle et al. (1975a), o glyphosate apresenta as seguintes constantes de dissoci ação, 2,0; 2,6; 5,6 e 10,6. Assim, a um pH $<2$ o glyphosate tem carga líquida positiva; de $\mathrm{pH}$ 2 a 2,6 tem carga zero ( $\mathrm{PCZ}=$ ponto de carga ze ro); e, acima do $\mathrm{pH}$ 2,6, te m carga líquida negativa que aumenta com o aumento de $\mathrm{pH}$. Com base ness as propriedades, verifica-se que a diferença de $\mathrm{pH}$ entre os dois' solos (Tabela 1) contribuiu para a pequena diferença de concentração nos solos estudados (Figura 9). Sob condições menos ácidas (solo de Sabará), a força de repulsão entre a superfície das argilas e a molécula do glyphosate é maior. Esse 
comportamento é resultado do aumento de cargas elétricas negativas na molécula, o que proporciona maior mobilidade para as camadas inferiores do solo. No solo de Viçosa, onde foi observado um pH mais ácido, a atuação das forças de adsorção mostraram-se mais intensas. Nessas condições de me nor repulsão das cargas dos colóides à molécula do glyphosate, houve aumento da atração, decorrente, provavelmente, das forças de van der Walls, pela at ração por pontes de hidrogênio entre o herbicida e a superfície hidratada da argila, assim como o de grupos carboxílicos, cetôni cos ou aminos da matéria orgânica e ainda, pela complexação com os íons metálicos $\mathrm{Fe}^{+++}$e $\mathrm{Al}^{+++}$, que podem, as si m, justificar es sa menor lixi viação no solo de Viçosa. A atuação dess as forças ad sortivas são significativas nos proces sos de inativação do glyphosate no solo, sendo que a mai or ou menor variação da adsorção entre solos é resultante de suas diferenças físicas,

químicas e mineralógicas (McConnell e Hossner, 1985; Miles e Moye 1988; Picollo et al., 1994 e Gerritse et al., 1996). Trabalhos desenvolvidos por Souza (1994) confirmaram a importância dessas variações nos fenômenos de adsorção do glyphosate em alguns solos

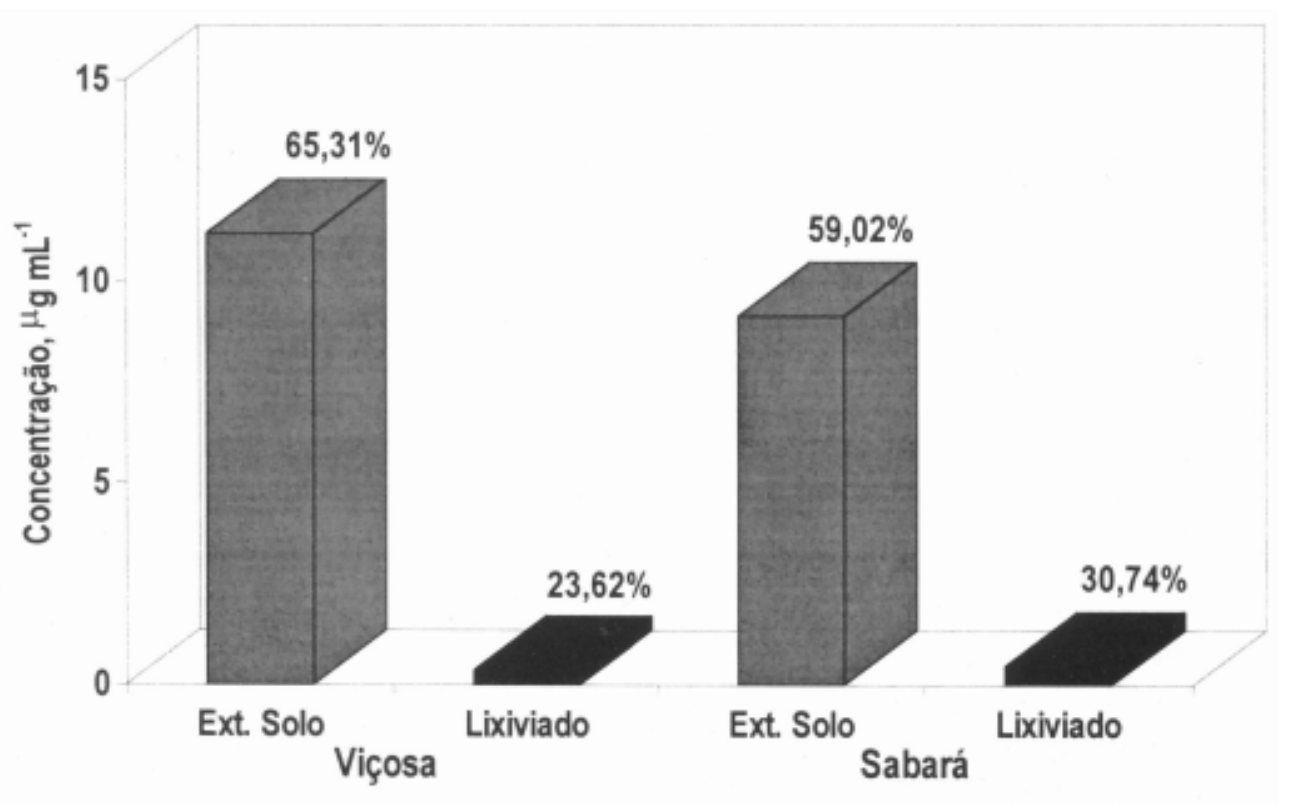

FIGURA 9. Concentração do glyphosa te nas amostras de solo e lixi viado da coluna de $1 \mathrm{~cm}$, e suas respectivas percentagens em relação ao conteúdo de glyphosate aplicado no solo.

$\mathrm{Na}$ Figura 10, são observados os cromatogramas de HPLC em soluções com diferentes concentrações do imazapyr. A identificação dessa molécula em água purificada, nas concentrações de $5 \mu \mathrm{g} \mathrm{L}^{-}{ }^{1}$ a $160 \mu \mathrm{g} \mathrm{L}^{-1}$, mostrou excelente resposta do detector, com picos bem definidos no tempo de 7,88 \pm 0,02 min. Esse comportamento obtido na curva-padrão em água purificada repetiu-se nas curvas em água de torneira e nas amostras de solo. Tais respostas associadas aos altos valores de coeficiente de de te rminação $\left(\mathrm{r}^{2}>0,98\right)$, ap re se nt ad os na Figura 11, dão um indicativo não somente a sensibilidade e especificidade do método cromatográfico (HPLC), como também do bom de sempenho no processo de preparação da amostra até sua injeção no cromatógrafo (Figura 5). 


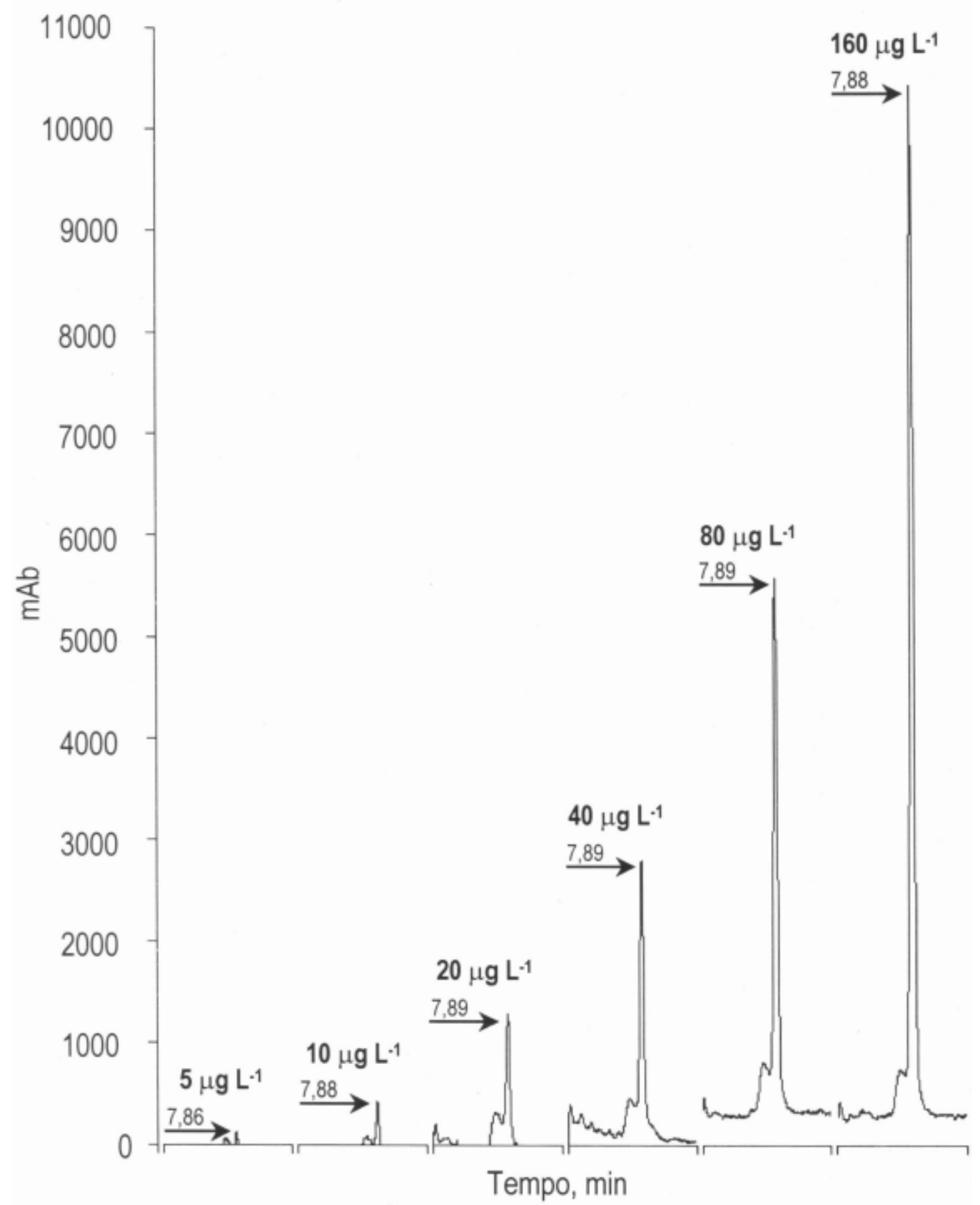

FIGURA 10. Cromatogramas de HPLC em soluções com diferentes concentrações do imazapyr.

A taxa de recupe ração do imazapyr nas amostras de água e de solo são apresentadas na Tabela 2. Observa-se, por esses dados, que o percentual de recupe ração do imazapyr nas amostras foram muito próximos de $100 \%$, apresentando também baixos valores no desvio-padrão (s). Tais resultados indicam que a metodologia adotada de preparo da amostra e extração do herbicida foi satisfatório permitindo uma maior segurança nas inferências apresentadas. 

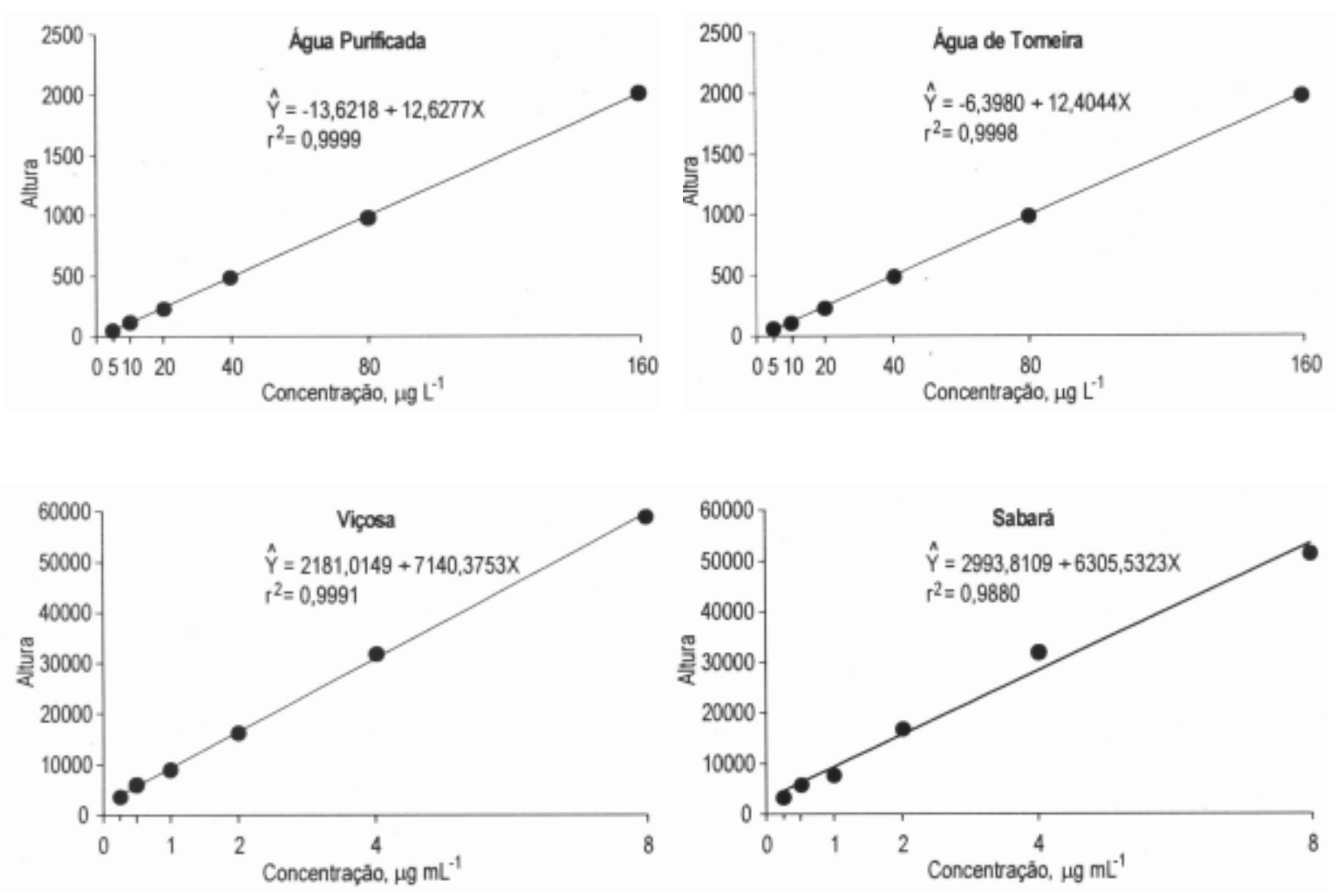

FIGURA 11. Curvas de calibração do imazapyr obtidas em água purific ada, água de torneira, solo de Viçosa e solo de Sabará. (média de duas repetições)

TABELA 2. Taxa de recu peração de $1 \mu \mathrm{g} \mathrm{mL}-{ }^{1}$ do imazapyr em amostra de água de torneira e solos de Viçosa e Sabará

\begin{tabular}{ccccccc}
\hline Repetição & \multicolumn{2}{c}{$\begin{array}{c}\text { Recuperação } \\
\text { Água }\end{array}$} & \multicolumn{2}{c}{$\begin{array}{c}\text { Recuperação } \\
\text { Viçosa }\end{array}$} & \multicolumn{2}{c}{$\begin{array}{c}\text { Recuperação } \\
\text { Sabará }\end{array}$} \\
\hline & $\mu \mathrm{g} \mathrm{mL}-1$ & $\%$ & $\mu \mathrm{g} \mathrm{mL}-1$ & $\%$ & $\mu \mathrm{g} \mathrm{mL}-1$ & $\%$ \\
1 & 1,0109 & 101,09 & 1,0051 & 100,51 & 1,0881 & 108,81 \\
2 & 1,0033 & 100,33 & 0,9376 & 93,76 & 1,0335 & 103,35 \\
3 & 0,9822 & 98,22 & 0,9525 & 95,25 & 0,9950 & 99,50 \\
\hline Média (m) & 0,9988 & 99,88 & 0,9651 & 96,51 & 1,0389 & 103,89 \\
\hline Desvio-Padrão (s) & 0,0149 & 1,49 & 0,0355 & 3,55 & 0,0468 & 4,68 \\
\hline
\end{tabular}

De acordo com a Figura 12, verificase que o imazapyr apresentou uma lixiviação diferenciada entre os solos estudados, sendo esta maior no solo franco-arenoso de Viçosa.
Observa-se, ainda, que, em razão dessa maior mobilidade no solo de Viçosa, houve um aumento da concentração com o aumento da profundidade, 
o que resultou em altas concentrações no lixiviado $\left(0,45 \mathrm{~g} \mathrm{~mL}^{-1}\right)$.

Em razão da presença do ácido carboxílico e das funções básicas do an el imidazolinona, a molécula do imazapyr exibe dois sítios de protonação: o nitrogênio do anel imi da zolinona e o grupo carboxil, que se dissociam com valores de pKa de 1,9 e 3,6, res pectiva me nte (We pplo, 1991). As si m, dependendo do $\mathrm{pH}$, o imazapyr pode se apresentar na solução do solo nas formas catiônic as, neutras e aniônicas (Pusino et al., 1997).

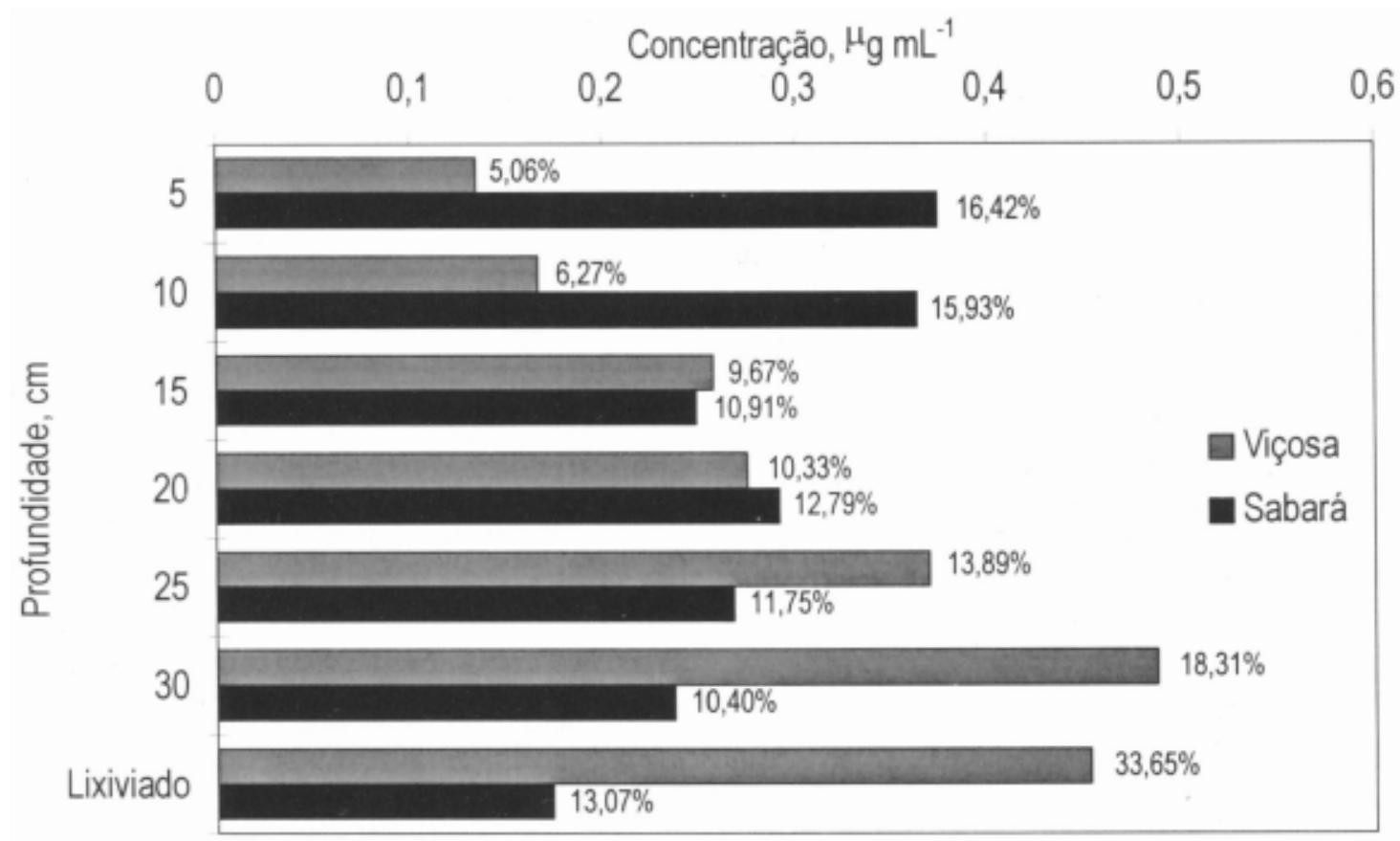

FIGUR A 12. Concen tra ção do imazapyr nas amo stras de solo, em difere nte s profun did ades, e no lixiviado da coluna de $30 \mathrm{~cm}$, e suas respectivas percentagens em relaçãoao conteúdo de imazapyr aplicado no solo franco-arenoso de Viçosa e argila de Sabará. (média de duas repetições).

Uma vez que os solos estudados se encontram a pH maiores que 3,6 (5,6 e 6,7 para Viçosa e Sabará, respectivamente), apen as a forma aniônica está disponível na solução do solo. Portanto, essa diferença de mobilidade (Figura 12) é resultante das diferenças físicas e químicas apresentadas por esses solos (Tabela 1). Observase, na Tabela 1, que o solo de Sabará apresen tou os mais altos valores de matéria orgânica $(0,74 \%$

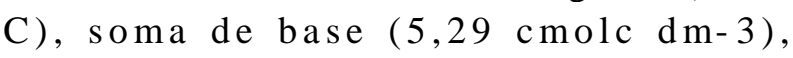
capacidade de troca de cátions (5,59 CTC total), saturação de bases $(94,6 \%$ V) e argila (44 dag $\mathrm{kg}^{\mathrm{I}}$ ), indicando que, pela natureza dos seus efeitos no complexo de troca do solo, o conjunto dessas características contribuíram para sua maior retenção nas profundidades iniciais $(5 \mathrm{e}$ $10 \mathrm{~cm}$ ), resultando em menores concentrações no lixiviado $\left(0,17 \mu \mathrm{g} \mathrm{mL}^{-1}\right)$. Sabe-se, no entanto, que a adsorção do imazapyr, em solos cujo $\mathrm{pH}$ da fase miscível encontra-se acima do PCZ do solo e da própria molécula, não ocorre por troca iônica e, sim, por forças não-iônicas (van der Waals, pontes de hidrogênio), que atuam em maior ou menor intensidade, de acordo com as variações físicas, químicas e mineralógicas desses solos (Pusino et al., 1997).

Em razão da dissociação do íon $\mathrm{H}^{+}$do grupo carboxílico e do anel imidazolinona, o 
imazapyr passa a apresentar, predominantemente, carga negativa e, nessa forma, há uma preferência em in te ragir com ou tras substâncias, sítios positivos da matéria orgânica e cátions metálicos $(\mathrm{Ca}++\mathrm{Mg}++, \mathrm{Cu}++, \mathrm{Fe}+++, \mathrm{Al}+++)$, que promoveriam um resíduo de carga líquida positiva no complexo, o que aumentaria a sua interação com a superfície das argilas do solo. Vizantinopoulos e Lolos (1994), estudando a persistência e lixiviação do imazapyr em dois solos com diferentes características físicas e químicas, verificaram elevada mobilidade dessa molécula nesses solos, sendo as diferenças de persistência e mobilidade apresentadas decorrentes, principalmente, do teor de argila e do conteúdo de matéria orgânica.

\section{LITERATURA CITADA}

BOWMER, K. Residues of glyphosate in irrigation water. Pestic. sci., v.13, p.623638,1982

BRoNSTAD, J.O., FRIESTAD, H.O. Method for determination of gly phosate residues in natural waters based on polarography of the $\mathrm{N}$-nitroso derivative. Analyst, v.101, p.820824, 1976.

CARLISLE, S.M., TREVORS, T. Glyphos ate in the environment. Water air soil pollut., n.39, p.409-420, 1988.

CHEA H, U., KIRK WO OD, C.R., LUM, K. Adsorption, desorption and mobility of four commonly used pesticides in Malaysian agricultural soils. Pestic. sci., v.50, p.53-63, 1997.

DAMANAKIS, M.E. Behaviour of glyphosate in the soil (adsorption, leaching and degradation). Ann. Inst. phytopathol.

Benaki, v.11, p.153-167, 1976.

DUDA, A.M., DYBA, M., KOZLOWSKI, H. et al. Copper(II) complexes of the imidazolinone herbicide imazapyr. J. agric. food chem m., v.44, n.11, p.3698-3702, 1996.

FRIESTAD, H.O., BRoNSTAD, J.O. Improved polarograohic for determination of glyph osate herbicide in crops, soil, and water. J. assoc. off. anal. chem., v.68, n.1, p.76-79, 1985.

GERRITSE, R.G., BELTRAN, J., HERNANDEZ, F. Adsorption of atrazine, simazine, and glyphosate in soil of the Gnangara Mound, Western Australia. Aust. j. soil res., n.34, p.599-607, 1996.

GLASS, R.L. Liquid chromatographic determination of glyphosate in fortified soil and water samples. J. agric. food chem., v.31, n.2, p.280-282, 1983.

GLAS S, R.L. Adsorption of glyphosate by soils and clay minerals. J. agric. food chem., v.35, n.4, p.497-500, 1987.

HANCE, R.J. Adsorption of glyphosate by soils.

Pest sci., v.7, p.363, 1976.

ISMAIL, B.S., AHMAD, A.R. Attenuation of the herbicidal activities of glufosinateammonium and imazapyr in two soils. Agric. ecosyst. environ., v.47, p.279-285, 1994.

LEE, A., GATTERDAM, P.E., CHIU, T.Y. et al. Plant metabolism. In: SHANER, D.L., O'CONNOR, S.L. (Eds.). The imidazolinone herbicides, Florida: CRC Press, Inc., 1991. p.151-165.

LIU, W., PUSINO, A., GESSA, C. High performance liquid chromatographic determination of the herbicide imazapyr residues in water and soil. . Sci. total environ., v.123/124, p.39-43, 1992. 
Mc CO NNELL, J.S ., HOS SNER, L.R.pH dependent adsorption isotherms of glyphosate. J. agric. food chem., v.33, n.6, p.1075-1078, 1985.

MICH AEL, J.L., NEAR Y, D. G. He rbicid e dissipation studies in southern for est ecosystems. Environ. toxicol. chem., v.12, p.405-410, 1993.

MILES, C.J., MOYE, A. Extraction of glyphosate herbicide from soil and clay minerals and determination of residues in soil. J. agric. food chem., v.36, n.3, p.486-491, 1988.

MOSHIER, L.J., PENNER, D. Factors influencing microbial degradation of ${ }^{14} \mathrm{C}$-glyphosate to ${ }^{14} \mathrm{CO}_{2}$ in soil. Weed sci., v.26, n.6, p.686691,1978 .

MULHOLLAND, M., HIBBERT, D.B. Linearity and the limitations of least squares calibration. J. chromatogr. A, v.792, p.7382, 1997.

NEWTON, M., HORNER, L.M., COWELL, J.E. et al. Dissipation of glyphosate and aminomethylphosphonic acid in North Americ an for ests. J. agric. food che m., v.42, n.8, p.1795-1802, 1994.

PICCOLO, A., CELANO, G., ARIENZO, M. et al. Adsorption and desorption of glyphosate in some European soils. J. environ. sci. health, Part B, n.6, p.1105-1115, 1994.

PICC OL O, A., CE LANO, G., CONTE, P. Ads or ption of glyphosate by humic substances. J. agric. food chem., v.44, n.8, p.2442-2446, 1996.

PUSino, A., PETRETTO, S., GESS A, C. Adsorption and desorption of imazapyr by so il. J. agric. food chem., v. 45, n.3, p.1012-1016, 1997.
ROY, D.N., KONAR, S.K., BANERJEE, S. et al. Persistence, movement, and degradation of glyphosate in selected Canadian Boreal forest soil. J. agric. food chem., v.37, n.2, p.437-440, 1989.

SANCHEZ-MARTIN, M.J., CRISANTO, T., ARIENZO, M. et al. Evaluation of the mobility of $\mathrm{C}^{14}$-labelled pesticides in soils by thin layer chromatography using a linear analyser. J. envi ron. sci. health, Part B, n.3, p.473-484, 1994.

SPRANKLE, P., MEGGITT, W.F., PENNER, D. Rapid inactivation of glyphosate in the soil. Weed sci., v.23, n.3, p.224-228, 1975a.

SPRANKLE, P., MEGGITT, W.F., PENNER, D. Ad so rption, mobility, and mi crobial degradation of glyphosate in the soil. Weed sci., v.23, n.3, p.229-234, 1975b.

SOUZA, A. P. de. Atividade do oxyfluorfen, 2,4D e glifosate, em solos de diferentes texturas na presença e na ausência de com posto orgânico. Viçosa, MG: UFV, 1994. 71p. Dissertação (Mestrado em Solos e Nutrição de Plantas) - Universidade Federal de Viçosa, 1994.

SUBRAMANIAM, V., HOGGARD, P.E. Metal complexes of gly phosate. J. agric. food chem., v.36, n.6, p.1326-1329, 1988.

TOR ST EN SS ON， N. T. L., AA MI SE PP, A. Detoxification of glyphosate in soil. Weed res., n.47, p.209-212, 1977.

VIZANTINOPOULOS, S., LOLOS, P. Persistence and leaching of the herbicide imazapyr in soil. Bull. environ. contam. toxicol., v.52, p.404-410, 1994.

WEHTJE, G., DICKENS, R., WILCUT, W.J. et al. Sorption and mobility of sulfometuron 
and imazapyr in five Alabama soils. Weed sci., v.35, n.6, p.858-864, 1987.

WEPPLO, P.J. Chemical and physical properties of the imidazolinones. In: SHANER, D.L., O'C ONNOR, S.L. (Eds.). The imidazolinone herbicides, Florida: CRC Press, Inc., 1991. p.15-20. 